\title{
RESEARCH
}

\section{Results of the Recent Immigrant Pregnancy and Perinatal Long-term Evaluation Study (RIPPLES)}

\author{
Joel G. Ray, Marian J. Vermeulen, Michael J. Schull, Gita Singh, Rajiv Shah, Donald A. Redelmeier
}

$\infty \quad$ See related article page 1439

\section{ABSTRACT}

Background: People who immigrate to Western nations may experience fewer chronic health problems than original residents of those countries, which raises concerns about long-term environmental or lifestyle factors in those countries. We tested whether the "healthy immigrant effect" extends to the risk of placental dysfunction during the short interval of pregnancy.

Methods: We conducted a population-based retrospective cohort study of data for 796105 women who had a first documented obstetric delivery in Ontario between 1995 and 2005. Recency of immigration was determined for each woman as the time from her enrolment in universal health insurance to her date of delivery, classified as less than 3 months, 3-5 months, 6-11 months, 12-23 months, 24-35 months, 36-47 months, 48-59 months and 5 years or more (the referent). The primary composite outcome was maternal placental syndrome (defined as a diagnosis of pre-eclampsia or eclampsia, placental abruption or placental infarction).

Results: The mean age of the women was 28.8 years. Maternal placental syndrome occurred in 45216 women (5.7\%). The risk of this outcome was lowest among the women who had immigrated less than 3 months before delivery (3.8\%) and highest among those living in Ontario at least 5 years $(6.0 \%)$, for a crude odds ratio (OR) of 0.62 (95\% confidence interval $[\mathrm{Cl}]$ 0.54-0.71). After adjustment for maternal age, income status, pre-existing hypertension, diabetes mellitus, multiple gestation and receipt of prenatal ultrasonography, the risk of maternal placental syndrome was correlated with the number of months since immigration in a gradient manner (OR, 95\% Cl): less than 3 months (0.53, 0.47-0.61), 3-5 months $(0.68,0.61-0.76), 6-11$ months (0.67, $0.63-0.71)$, 12-23 months (0.69, 0.66-0.73), 24-35 months (0.75, 0.70$0.79), 3^{6-47}$ months $(0.75,0.70-0.80)$ and $48-59$ months $(0.82,0.77-0.87)$.

Interpretation: There was a progressively lower risk of maternal placental syndromes associated with recency of immigration. The "healthy immigrant effect" may extend to common placental disorders, diminishes with the duration of residency and underscores the importance of nongenetic determinants of maternal health accrued over a brief period.

CMAJ 2007;176(10):1419-26
$\mathrm{P}$ eople who immigrate to Western countries are believed to experience fewer chronic health problems than individuals born in those countries. ${ }^{1,2}$ For example, new immigrants have been found to have lower rates of diabetes mellitus, hypertension, heart disease and cancer the so-called "healthy immigrant effect." In addition, an inverse relation may exist between time since arrival and the risk of some chronic conditions. ${ }^{3}$ Immigrants have also been shown to have more disability-free years and longer life expectancies than people born in Canada. ${ }^{4,5}$ In addition, preliminary studies have indicated a less significant risk of infant mortality and low birth weight among offspring of women who settle in the United States than among their American-born counterparts. ${ }^{5-7}$ However, data on obstetric outcomes are lacking.

Prior research was principally restricted to the study of chronic conditions, and a woman's duration of residency in her adopted country was not evaluated. As a consequence, the observed health advantage might be confounded by factors such as changing immigration policy (e.g., only healthy candidates are given visas) or detrimental nongenetic hazards (e.g., the lifestyle or nutrition of North Americans is less healthy). Another limitation of past research is that some individuals would not be captured within administrative health care databases, since free and universal health care was not available to most participants; ${ }^{5,7}$ this might bias against the inclusion of the most disadvantaged or least healthy immigrants, since they are less likely to qualify for health insurance soon after their arrival in a new country. ${ }^{8}$

Ontario is Canada's most populated province and one of the most ethnically diverse places in the world. There are 2.2 million individuals of visible minority in Ontario, accounting for $19 \%$ of the province's population, and about I20 ooo people immigrate to the province each year' (Appendix I). With a universal health care system that entitles all residents to receive comprehensive prenatal and postnatal care, Ontario maintains detailed computerized medical records of all health care services and obstetric deliveries. In this study, we evaluated the short-term risk of maternal placental syndrome (defined as pre-eclampsia or eclampsia, placental abruption or placental infarction ${ }^{10}$ ) in association with recency of immigration over a range of relatively brief intervals. Our hypothesis was that a healthy immigrant effect would be seen within the short period of pregnancy and manifest as a declining gradient related to duration of residence in Ontario. 


\section{Methods}

The Recent Immigrant Pregnancy and Perinatal Long-term Evaluation Study (RIPPLES) is a retrospective populationbased cohort study. It included all women who were residents and landed immigrants in Ontario admitted to hospital between Apr. I, I995, and Feb. 28, 2005, for a first obstetric delivery of a liveborn or stillborn infant after 20 weeks' gestation. The women had to be enrolled in the Ontario Health Insurance Plan (OHIP), which covers most aspects of health care and for which there is no user fee. Only the first delivery was considered if a woman had more than one event during the study period. We excluded women under I 4 years of age or over 50 years of age at delivery, those who were not residents of Ontario and those without a valid OHIP health card number. Obstetric delivery was determined on the basis of a main patient service code (Appendix 2). The gravidity or parity of each participant was not known.

The primary composite outcome was maternal placental syndrome, defined as a diagnosis of pre-eclampsia or eclampsia (typically based on the presence of hypertension in association with at least $2+$ protein on a urine dipstick or at least $300 \mathrm{mg}$ of protein in a 24-hour collection of urine), placental abruption or placental infarction during the index admission for obstetric delivery. The International Classification of Diseases 9 th revision (ICD-9) and roth revision (ICD-Io) coding systems were used to identify each outcome (Appendix 2).

The primary study exposure was recency of immigration to Ontario relative to the date of delivery. We classified time intervals as less than 3 months, $3-5$ months, $6-$ II months, I223 months, 24-35 months, 36-47 months, 48-59 months and 5 or more years. The time of immigration to Ontario was approximated using each woman's date of eligibility for OHIP (see www.university.ca/eng/canadainfo/healthcare /onthealth.htm for details [accessed 2006 July I]). Women categorized as having been in Ontario 5 or more years may have either been born in the province or had immigrated many years before delivery.

The study was completed using 3 deterministically linked provincial health care administrative databases. Hospital admission records were obtained from the Canadian Institute for Heath Information Discharge Abstract Database, which was used to identify obstetric deliveries as well as related study outcomes (see Appendix 2). The anonymous discharge abstracts contain the unique encrypted health card number, the age and sex of the individual, the date of admission and up to 16 diagnoses in ICD-9 codes, and up to 25 diagnoses in ICD-Io (Appendix 2). The date of issue of a health insurance number, used as a proxy for the date of arriving in Ontario, was retrieved from the Registered Persons Database, which contains health care identifiers for all eligible individuals. To avoid counting women who emigrated from and then returned to Ontario, we excluded those with more than one OHIP eligibility record, defined as the presence of multiple start dates in the Registered Persons Database eligibility file after Apr. I, I990.

Since some conditions (e.g., pre-existing hypertension and diabetes mellitus) may have been diagnosed on an outpatient basis, we used the OHIP database to identify covariates exist- ing up to I year before the index delivery (Appendix 2). This database contains records of all physician billing information for outpatient and inpatient services, including a service date and a single diagnosis. Area of residence (rural v. urban) and income fifth (i.e., income quartile) were defined according to postal code information and Statistics Canada census data.

For statistical analysis, we compared maternal characteristics in relation to recency of immigration using one-way analysis of variance for continuous variables and the $\chi^{2}$ test for categorical data. The main analysis examined the associated risk between recency of arrival in Ontario and development of maternal placental syndrome during the index admission for obstetric delivery. We obtained crude and adjusted odds ratios (ORs) and 95\% confidence intervals (CIs) using logistic regression analysis, with the group of women whose time since immigration was 5 or more years serving as the referent. The OR was adjusted for those variables listed in Appendix 2. We chose to control for receipt of prenatal ultrasonography at I2-24 weeks' gestation (based on an assumed confinement of 40 weeks' gestation) as a reflection of access to prenatal care ${ }^{11}$ and because early detection of fetal anomalies may affect subsequent care (e.g., pregnancy termination). We did not adjust for maternal obesity because it is poorly captured in the databases, based on our prior experience, ${ }^{10}$ and maternal weight was not measured herein.

Assessment of the outcome maternal placental syndrome was also categorized by maternal age $(<20,20-34,35-39$, and $\geq 40$ years), urban and rural place of residence, and lowest and highest income fifths (i.e., quintiles), using the same covariates as before (Appendix 2). To account for women who were not eligible for OHIP coverage at the time of delivery, we included them in a "no OHIP" group. Although they were not compared with other women in the bivariate and multivariable analyses, the study outcomes were reported in the form of a number and rate for this group.

All $p$ values were 2 -sided, at a significance level of 0.05 . The health care databases were linked anonymously using encrypted individual health card numbers. Our study did not rely on individual-level consent and followed safeguards for patient confidentiality established by the Institute for Clinical Evaluative Sciences in Ontario. The Ethics Committee of Sunnybrook Health Sciences Centre granted approval for this study.

\section{Results}

A total of I 278753 deliveries occurred during the Io-year study interval, of which 871507 were a first delivery. Of these first deliveries, 2800 women did not have a valid residential postal code, 263 were outside of the study age limits, 7I 52I had more than one OHIP eligibility record, and 8I8 were not eligible for OHIP coverage at the time of delivery (the "no OHIP" group). In all, 796 ro5 women were included in the final cohort (Table I).

We observed a minor difference in mean maternal age between the most recent immigrants and those living in Ontario for 5 or more years ( 28.6 v. 28.8 years respectively). Conversely, the prevalence of low-income status (lowest income fifth) was about $35 \%$ among women who were within 3 years of immigration, compared with $20 \%$ among long-term residents (Table I). The rates of pre-existing hypertension, obe- 
sity, depression and asthma increased proportionately with increasing length of residency. Indeed, tobacco dependence was approximately 4 times higher among long-term residents than among the most recent immigrants (0.4\% v. 0.I\%). The rate of multigestational pregnancy was approximately $\mathrm{I} \%$, with little difference between the groups. Use of prenatal ultrasonography among immigrants living in Ontario at least 6 months was similar to the rate among long-term residents (Table I).

There were 45 2I 6 women (5.7\%) who experienced maternal placental syndrome during the study. The risk of this outcome was lowest among women who had immigrated within 3 months before delivery (3.8\%), rising progressively with longer time since arrival (Table 2). The relative odds of this outcome was $38 \%$ lower among the most recent immigrants than among the long-term residents; the odds were even more pronounced in the adjusted model (Table 2). Even women who had immigrated 48-59 months before the index delivery were at lower risk of maternal placental syndrome than those residing 5 or more years in Ontario (adjusted OR 0.82 , 95\% CI 0.77-0.87) (Table 2).

The pattern of decreased risk of maternal placental syndrome with recency of immigration was especially evident among women aged 20-34 years (Fig. I), who represented about $80 \%$ of the study population. Women residing in an urban setting also displayed an accentuated gradient. Women in both the lowest and highest income fifths demonstrated a significantly lower risk of material placental syndrome associated with shorter residence in Ontario compared with residence of 5 or more years. No significant gradient was observed among women living in rural areas (Fig. I).

In total, 29 92I women (3.8\%) developed pre-eclampsia or eclampsia (Table 3). The relative odds of this outcome was about 35\% lower among women who had been in Ontario less than 2 years, and about 25\% lower among those in the province 48-59 months, than among women who had been in Ontario 5 or more years (Table 3 ). Similar trends were seen among the I6 64I women who had a diagnosis of placental abruption or infarction (Table 3 ).

Of the 818 women (o.r\%) in the "no OHIP" group, 40 (4.9\%) experienced maternal placental syndrome, a rate slightly lower than that of $5.7 \%$ for the entire cohort. The respective rates also differed slightly for pre-eclampsia or eclampsia (2.8\% v. 3.8\%), placental abruption (I.7\% v. I.2\%) and placental infarction (0.9\% v. I.0\%).

Table 1: Maternal characteristics according to recency of immigration before index delivery

\begin{tabular}{|c|c|c|c|c|c|c|c|c|c|}
\hline Characteristic* & \multicolumn{8}{|c|}{ Recency of immigration before index delivery; no. (\%) of woment } & $p$ value \\
\hline $\begin{array}{l}\text { Age, yr, } \\
\text { mean (SD) }\end{array}$ & $28.6(5.3)$ & $28.1(5.3)$ & $27.7(5.1)$ & $28.8(5.1)$ & $29.3(5.1)$ & $29.3(5.1)$ & $29.4(5.1)$ & $28.8(5.7)$ & $<0.001$ \\
\hline $\begin{array}{l}\text { Urban } \\
\text { residence }\end{array}$ & 5675 (95.9) & 7538 (96.2) & $27028(97.5)$ & 31558 (96.9) & $24286(96.8)$ & $21704(96.3)$ & 22453 (94.5) & $567993(87.3)$ & $<0.001$ \\
\hline 1 (lowest) & $2080(35.1)$ & $2824(36.0)$ & $10870(39.2)$ & $11833(36.4)$ & $8689(34.6)$ & 7167 (31.8) & $7380(31.0)$ & $130152(20.0)$ & \\
\hline 2 & $1336(22.6)$ & $1852(23.6)$ & $6638(23.9)$ & 7507 (23.1) & $5632(22.4)$ & $5105(22.6)$ & $5090(21.4)$ & $132250(20.3)$ & \\
\hline 3 & $958(16.2)$ & $1255(16.0)$ & 4405 (15.9) & 5389 (16.6) & $4190(16.7)$ & $3877(17.2)$ & $4114(17.3)$ & $131910(20.3)$ & \\
\hline 4 & $752(12.7)$ & 969 (12.4) & $2960(10.7)$ & $4008(12.3)$ & 3368 (13.4) & 3247 (14.4) & $3576(15.0)$ & $131435(20.2)$ & \\
\hline 5 (highest) & $622(10.5)$ & $774 \quad(9.9)$ & $2223 \quad(8.0)$ & 3111 (9.6) & $2662(10.6)$ & $2582(11.5)$ & 3037 (12.8) & $109364(16.8)$ & $<0.001$ \\
\hline Obesity & $4 \quad(0.1)$ & $22 \quad(0.3)$ & $111(0.4)$ & $288 \quad(0.9)$ & $229 \quad(0.9)$ & $261 \quad(1.2)$ & 312 & 10529 & $<0.001$ \\
\hline $\begin{array}{l}\text { Tobacco } \\
\text { dependence }\end{array}$ & $6 \quad(0.1)$ & $13 \quad(0.2)$ & $45 \quad(0.2)$ & $27 \quad(0.1)$ & $24 \quad(0.1)$ & $22 \quad(0.1)$ & $37 \quad(0.2)$ & $2838 \quad(0.4)$ & $<0.001$ \\
\hline Depression & $16 \quad(0.3)$ & $24 \quad(0.3)$ & $179 \quad(0.6)$ & $319 \quad(1.0)$ & $284 \quad(1.1)$ & $274 \quad(1.2)$ & $316 \quad(1.3)$ & 10930 & $<0.001$ \\
\hline Asthma & $19 \quad(0.3)$ & $\begin{array}{ll}71 & (0.9)\end{array}$ & $385 \quad(1.4)$ & $735 \quad(2.3)$ & $640 \quad(2.6)$ & $670 \quad(3.0)$ & $808 \quad(3.4)$ & $30658 \quad(4.7)$ & $<0.001$ \\
\hline $\begin{array}{l}\text { Multigestational } \\
\text { pregnancy }\end{array}$ & $55 \quad(0.9)$ & $97 \quad(1.2)$ & $206 \quad(0.7)$ & $242 \quad(0.7)$ & $255 \quad(1.0)$ & $252 \quad(1.1)$ & $260 \quad(1.1)$ & $8043 \quad(1.2)$ & $<0.001$ \\
\hline $\begin{array}{l}\text { Prenatal } \\
\text { ultrasound at } \\
12-24 \text { weeks' } \\
\text { gestation } 9\end{array}$ & $19 \quad(0.3)$ & $2374(30.3)$ & $24019(86.6)$ & $28860(88.7)$ & $22453(89.5)$ & $20012(88.8)$ & $20967(88.2)$ & $588892(90.5)$ & $<0.001$ \\
\hline
\end{tabular}

*See Appendix 2 for details of each characteristic.

†Unless stated otherwise.

$\neq$ Compares each maternal characteristic using one-way analysis of variance for continuous variables and the $\chi^{2}$ test for categorical data.

$\S$ The sum of numbers in each column may not equal the column total because the income fifth could not be estimated for a small proportion (<3\%) of women.

IUltrasounds performed before arrival in Ontario were not measured; therefore, rates among women who immigrated < 6 months before the index delivery may be underestimated. 


\section{Interpretation}

We found a progressively lower risk of maternal placental syndrome associated with recency of immigration. Women who immigrated within 3 months before delivery exhibited about a $40 \%$ lower relative risk of the syndrome than women who had been living in Ontario for 5 or more years. This gradient was seen for the majority of women living in urban centres, as well as across highest and lowest income strata.

Because we found that new immigrant women were at lower risk of maternal placental syndrome than women who had been living in Ontario for 5 or more years, it rebuts the common perception that immigrants might consume more health care resources than do long-term residents. ${ }^{3,20}$ This is not likely to be explained by lack of access to health resources, as might be the case under US Medicaid, ${ }^{21,22}$ since OHIP provides universal prenatal and general health care coverage. Rather, the "healthy immigrant" gradient may partly explain this phenomenon. Recent immigrants in our study were found to have lower rates of obesity and hypertension (Table I), a finding supported by results from other studies involving nonpregnant adults. ${ }^{1-3,5,8}$ It is conceivable that this may "protect" them against maternal placental syndrome, since obesity, pre-existing hypertension and diabetes mellitus are independent risk factors for placental dysfunction. ${ }^{23-25}$ However, as new immigrant women progressively adopt a Western-style diet and lifestyle, a process known as "convergence," ${ }^{18,26,27}$ their risk of obesity may increase parallel to their duration of residence. ${ }^{26,28-30}$ It may take only 5-10 years following immigration for a woman to lose her baseline healthy body weight ${ }^{28,29}$ and assume a risk profile similar to that of long-term residents. ${ }^{17,30,31}$

In 2 studies of chronic disease in nonpregnant adults, the "healthy immigrant effect" was lost after 30 years of residence in Canada. ${ }^{3,28}$ However, in RIPPLES, the risk of maternal placental syndrome tended to converge after only 5 years after immigration. This effect may be explained, to a degree, by the brief and sensitive developmental window of the placental vasculature ${ }^{32}$ which depends on maternal well-being from about the time of conception to about 18 weeks' gestation. ${ }^{25}$ Our results suggest that specific factors involved in the development of maternal placental syndrome may have a much more immediate effect and are worthy of exploration.

The observed association between recency of immigration and maternal placental syndrome was limited to urban centres. This is not surprising, given that most immigrants in Ontario live in large cities. ${ }^{9}$ Conversely, immigrants comprise just $9 \%$ of the populace of rural Ontario. ${ }^{33}$ Since a gradient effect between recency of arrival and maternal placental syndrome was seen across income fifths, it is unlikely that economic factors and access to care explain much of this difference. Moreover, a larger proportion of new immigrants who settle in rural Canadian areas have a university degree. ${ }^{33}$

Our study had limitations. Although we attempted to capture all women admitted to hospital for an obstetric delivery in Ontario during the study period, a small number did not have OHIP coverage. However, their rate of maternal placental syndrome was only slightly lower than the rate for the entire cohort, and they comprised just $0.1 \%$ of all recorded deliveries. Our method of using the date of enrolment in universal health insurance as an adequate approximation of the time of arrival to Ontario has not been validated. Any misclassification of recency of immigration would likely have attenuated our findings. Moreover, the presence of a dose-response effect suggests that most women were appropriately classified. We did not possess information about parity, a predictor of pre-eclampsia risk. Parity may have differed among the study groups; for example, among women who recently arrived in Ontario, those from mainland China, where a onechild policy exists, may have had a different parity than that of women from other parts of Canada or other countries without such a policy.

We did not account for the possibility that ethnic differences across groups may explain the observed association be-

Table 2: Risk of maternal placental syndrome in association with recency of immigration

\begin{tabular}{|c|c|c|c|c|}
\hline \multirow{2}{*}{$\begin{array}{l}\text { Recency of } \\
\text { immigration, months }\end{array}$} & \multicolumn{2}{|c|}{$\begin{array}{c}\text { Maternal placental syndrome; } \\
\text { no. (\%) of women }\end{array}$} & \multirow{2}{*}{$\begin{array}{l}\text { Unadjusted OR } \\
\qquad(95 \% \mathrm{Cl})\end{array}$} & \multirow{2}{*}{$\begin{array}{l}\text { Adjusted OR* } \\
\qquad(95 \% \mathrm{Cl})\end{array}$} \\
\hline & Present & Absent & & \\
\hline$<3(n=5920)$ & $225(3.8)$ & $5695(96.2)$ & $0.62(0.54-0.71)$ & $0.53(0.47-0.61)$ \\
\hline $3-5(n=7835)$ & $359(4.6)$ & $7476(95.4)$ & $0.76(0.68-0.84)$ & $0.68(0.61-0.76)$ \\
\hline $6-11(n=27734)$ & $1076(3.9)$ & $26658(96.1)$ & $0.63(0.60-0.68)$ & $0.67(0.63-0.71)$ \\
\hline $12-23(n=32556)$ & $1333(4.1)$ & 31223 (95.9) & $0.67(0.64-0.71)$ & $0.69(0.66-0.73)$ \\
\hline $24-35(n=25095)$ & $1121(4.5)$ & 23974 (95.5) & $0.74(0.69-0.78)$ & $0.75(0.70-0.79)$ \\
\hline $36-47(n=22540)$ & $1012(4.5)$ & 21528 (95.5) & $0.74(0.69-0.79)$ & $0.75(0.70-0.80)$ \\
\hline $48-59(n=23772)$ & $1165(4.9)$ & 22607 (95.1) & $0.81(0.76-0.86)$ & $0.82(0.77-0.87)$ \\
\hline$\geq 60(n=650653)$ & $38925(6.0)$ & $611728(94.0)$ & $1.0 \dagger$ & $1.0 \dagger$ \\
\hline
\end{tabular}

Note: $\mathrm{OR}=$ odds ratio, $\mathrm{Cl}=$ confidence interval.

*Adjusted for maternal age (continuous, in years), income fifth, pre-existing hypertension (yes/no), diabetes mellitus (yes/no), multiple gestation (yes/no) and receipt of prenatal ultrasonography at 12-24 weeks' gestation (yes/no). †Reference group. 


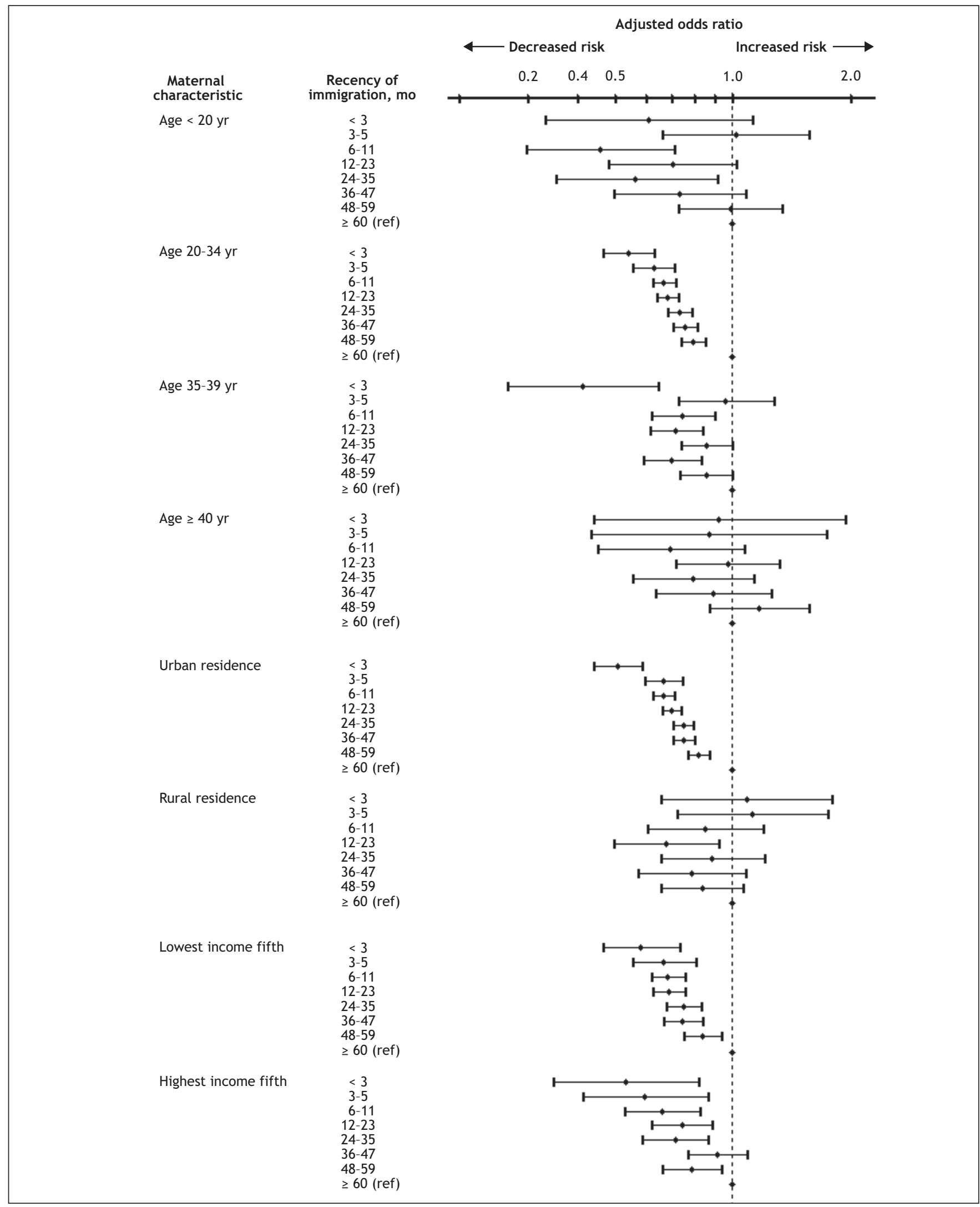

Fig. 1: Risk of maternal placental syndrome (pre-eclampsia or eclampsia, placental abruption or placental infarction) among 796105 women in association with recency of immigration, stratified by maternal demographic characteristics. Error bars $=95 \%$ confidence intervals; ref = reference group. 
Table 3: Risk of pre-eclampsia or eclampsia and placental abruption or infarction in association with recency of immigration

\begin{tabular}{|c|c|c|c|c|c|c|}
\hline $\begin{array}{l}\text { Recency of } \\
\text { immigration, months }\end{array}$ & \multicolumn{3}{|c|}{ Pre-eclampsia or eclampsia $(n=29921)^{*}$} & \multicolumn{3}{|c|}{ Placental abruption or infarction $(n=16641)^{*}$} \\
\hline$<3(n=5920)$ & $131(2.2)$ & $0.54(0.46-0.65)$ & $0.66(0.53-0.75)$ & $103(1.7)$ & $0.80(0.66-0.98)$ & $0.46(0.37-0.56)$ \\
\hline $3-5(n=7835)$ & $223(2.8)$ & $0.70(0.61-0.80)$ & $0.78(0.68-0.89)$ & $148(1.9)$ & $0.87(0.74-1.03)$ & $0.58(0.49-0.69)$ \\
\hline $6-11(n=27734)$ & $662(2.4)$ & $0.59(0.54-0.63)$ & $0.64(0.59-0.69)$ & $442(1.6)$ & $0.74(0.67-0.81)$ & $0.73(0.66-0.81)$ \\
\hline $24-35(n=25095)$ & $710(2.8)$ & $0.70(0.65-0.75)$ & $0.72(0.67-0.78)$ & $452(1.8)$ & $0.83(0.76-0.92)$ & $0.82(0.75-0.90)$ \\
\hline $36-47(n=22540)$ & $626(2.8)$ & $0.69(0.63-0.74)$ & $0.71(0.65-0.76)$ & $418(1.9)$ & $0.86(0.78-0.95)$ & $0.84(0.76-0.93)$ \\
\hline $48-59(n=23772)$ & $721(3.0)$ & $0.75(0.70-0.81)$ & $0.77(0.71-0.83)$ & $472(2.0)$ & $0.92(0.84-1.01)$ & $0.89(0.81-0.98)$ \\
\hline$\geq 60(n=650653)$ & $26055(4.0)$ & $1.0 \neq$ & $1.0 \neq$ & $14033(2.2)$ & $1.0 \neq$ & $1.0 \neq$ \\
\hline
\end{tabular}

Note: $\mathrm{OR}=$ odds ratio, $\mathrm{Cl}=$ confidence interval.

*The total number of women in this table is greater than the study population because 1346 women experienced both pre-eclampsia or eclampsia and a placental abruption or infarction.

†Adjusted for maternal age (continuous, in years), income fifth, pre-existing hypertension (yes/no), diabetes mellitus (yes/no), multiple gestation (yes/no) and receipt of prenatal ultrasonography at 12-24 weeks' gestation (yes/no).

$\ddagger$ Reference group.

tween recency of immigration and maternal placental syndrome. ${ }^{14,15}$ At the same time, the relation between race and maternal placental syndrome may be determined in part by maternal age ${ }^{16}$ which was controlled for. We do not believe that the observed gradient can be attributed to a differential "work-up bias," where a recent immigrant is neglected and any placental dysfunction is therefore missed. For example, it is unlikely that a label of pre-eclampsia, a common condition diagnosed using standard clinical methods available in all hospitals, would be applied differentially to certain women in RIPPLES, especially since all were enrolled in a universal health care system.

The health screening process for new immigrants to Canada consists of an immigration medical examination designed to identify inadmissible candidates, including people with end-stage organ disease, certain cancers and infectious diseases, and those who require long-term nursing care. This screening process has remained relatively constant over time ${ }^{17}$ such that recent immigrants (e.g., arriving within I2 months) would not be expected to be healthier at the time of screening than immigrants who have been here longer (e.g., 3-5 years). Moreover, the above exclusion criteria would likely apply to a small number of women of reproductive age. ${ }^{18}$ It is also improbable that a change to Canada's immigration policy can explain the observed protective effect over the Io-year study period, during which time the ethnic composition of its new immigrants remained relatively stable. ${ }^{3,9}$ Data for the period I99I-200I show that only $2.5 \%$ of new immigrants to Ontario originated from elsewhere in North America; the majority emigrated from Asia (58\%) (Appendix I). The latter may be important, since maternal and paternal ethnicity predict risk of maternal placental syndrome, with couples of Asian ancestry demonstrating a lower risk of pre-eclampsia than other ethnic groups. ${ }^{19}$ However, we could not account for differences in the countries of origin between recent and long-term immigrants to
Ontario. Future studies should detail both the ethnic composition of pregnant women and their partners as well as their country of origin.

Another limitation was that the data regarding preexisting conditions (e.g., hypertension, diabetes mellitus and obesity) may not have been complete for the women who arrived in Ontario within 12 months before delivery. These variables were probably adequately captured by I 2 months, however, since OHIP billing claims are known to increase sharply by 3 months after arrival to Ontario. ${ }^{\mathrm{I2}}$ In addition, the rates of antenatal ultrasonography were similar among the women who immigrated 6-II months before delivery as among those who had longer OHIP eligibility (Table I). In a validation study of a large Swedish birth registry, similar to the Discharge Abstract Database used in RIPPLES, the positive predictive value of a diagnosis of pre-eclampsia was $96 \% .{ }^{13}$ Although not formally validated in the Discharge Abstract Database, placental abruption and infarction are likely adequately captured by a mandatory field in the Ontario birth record, which is completed by the delivering physician or midwife, who describes the gross appearance of the placenta.

A reasonable public health recommendation based on the findings from RIPPLES and other studies is that we should aim to preserve the apparent healthier state of new immigrant women through policies designed to discourage the adoption of adverse lifestyle choices. For long-term immigrants and native-born residents, the goal should be to improve their health status. Common to all should be consideration of the prevention of obesity and the optimization of nutrition before pregnancy, by promoting controlled energy intake and higher energy expenditure in childhood, adolescence and early adulthood. ${ }^{25,34,35}$ This approach may also translate into long-term health benefits for women at high risk of maternal placental syndrome, regardless of their immigration status or pregnancy outcome..$^{10,36}$ 


\section{This article has been peer reviewed.}

From the Departments of Medicine (Ray), Obstetrics and Gynecology (Ray, Shah), and Health Policy Management and Evaluation (Ray), St. Michael's Hospital and University of Toronto; the Institute for Clinical Evaluative Sciences, University of Toronto (Vermeulen, Schull, Redelmeier); the Division of Emergency Medicine (Schull), the Department of Medicine (Redelmeier) and the Department of Health Policy Management and Evaluation (Schull, Redelmeier), Sunnybrook Health Sciences Centre; and the Centre for Research on Inner City Health, St. Michael's Hospital (Singh), Toronto, Ont.

Competing interests: None declared.

Contributors: All of the authors participated in the design, data analysis and writing of the paper and approved the final version.

Acknowledgements: We thank Kelvin Lam for his assistance in conducting some of the data analyses.

Joel Ray and Michael Schull are supported by Canadian Institutes of Health Research New Investigator Awards. Donald Redelmeier holds a Canada Research Chair in Medical Decision Science.

\section{REFERENCES}

I. Gee EM, Kobayashi KM, Prus SG. Examining the healthy immigrant effect in midto later life: findings from the Canadian Community Health Survey. Can J Aging 2004;23(Suppl I):S6I-9.

2. Kliewer E. Epidemiology of diseases among migrants. Int Migr 1992;30:I4I-64.

3. Ali JS, McDermott S, Gravel RG. Recent research on immigrant health from statistics Canada's population surveys. Can J Public Health 2004;95:I9-I3.

4. Chen J, Wilkins R, Ng E. Health expectancy by immigrant status, I986 and I99I. Health Rep 1996;8:29-38.

5. Singh GK, Miller BA. Health, life expectancy, and mortality patterns among immigrant populations in the United States. Can J Public Health 2004;95:Ir4-2I.

6. Singh GK, Yu SM. Adverse pregnancy outcomes: differences between US- and foreign-born women in major US racial and ethnic groups. Am J Public Health I996;86:837-43.

7. Wingate MS, Alexander GR. The healthy migrant theory: variations in pregnancy outcomes among US-born migrants. Soc Sci Med 2006;62:49I-8.

8. Bolen JC, Rhodes L, Powell-Griner EE, et al. State-specific prevalence of selected health behaviors, by race and ethnicity - Behavioral Risk Factor Surveillance System, I997. MMWR CDC Surveill Summ 2000;49:I-6o.

9. Census 200I highlights: factsheet 5: immigration to Ontario. Toronto: Ontario Minstry of Finance; 2003. Available: www.fin.gov.on.ca/english/economy /demographics/census/cenhi5. html (last modified 2007 Jan 26; accessed 2007 Apr 2).

Io. Ray JG, Vermeulen MJ, Schull MJ, et al. Cardiovascular health after maternal placental syndromes (CHAMPS): population-based retrospective cohort study. Lancet 2005;366:1797-803.

II. Rowe RE, Garcia J, Davidson LL. Social and ethnic inequalities in the offer and uptake of prenatal screening and diagnosis in the UK: a systematic review. Public Health 2004;118:177-89.

I2. DesMeules M, Gold J, Kazanjian A, et al. New approaches to immigrant health assessment. Can J Public Health 2004:95:I22-6.

13. Ros HS. Preeclampsia and other circulatory diseases during pregnancy - etiological aspects and impact on female offspring [thesis]. Stockholm: Karolinska University Press; 200I.

I4. Gardner MO, Goldenberg RL. The influence of race and previous pregnancy outcome on outcomes in the current pregnancy. Semin Perinatol I995;19:19I-6.

I5. Baker AN, Hellerstedt WL. Residential racial concentration and birth outcomes by nativity: Do neighbors matter? J Natl Med Assoc 2006;98:172-80.

I6. Buescher PA, Mittal M. Racial disparities in birth outcomes increase with maternal age: recent data from North Carolina. NC Med J 2006;67:I6-20.

I7. Gushulak BD, Williams LS. National immigration health policy: existing policy, changing needs, and future directions. Can J Public Health 2004;95:I27-9.

I8. Beiser M. The health of immigrants and refugees in Canada. Can J Public Health 2005;96(Suppl 2):S30-44.

I9. Caughey $\mathrm{AB}$, Stotland $\mathrm{NE}$, Washington $\mathrm{AE}$, et al. Maternal ethnicity, paternal ethnicity, and parental ethnic discordance: predictors of preeclampsia. Obstet $G y-$ necol 2005; I06:156-6I.

20. Fix M, Zimmerman W. Welfare reform: a new immigrant policy for the United States. Washington: Urban Institute; 1997.

2I. Leclere FB, Jensen L, Biddlecom AE. Health care utilization, family context, and adaptation among immigrants to the United States. J Health Soc Behav I994;35:370-84.

22. Ku L, Matani S. Left out: immigrants' access to health care and insurance. Health Aff (Millwood) 2001;20:247-56

23. Ostlund I, Haglund B, Hanson U. Gestational diabetes and preeclampsia. Eur J Obstet Gynecol Reprod Biol 2004; II 3:I2-6.

24. Sibai BM, Caritis S, Hauth J, et al. Risks of preeclampsia and adverse neonatal outcomes among women with pregestational diabetes mellitus. National Institute of Child Health and Human Development Network of Maternal-Fetal Medicine Units. Am J Obstet Gynecol 2000;182:364-9.

25. Ray JG, Vermeulen MJ, Schull MJ, et al. Metabolic syndrome and the risk of placental dysfunction. J Obstet Gynaecol Can 2005;27:1095-101

26. Tremblay MS, Perez CE, Ardern CI, et al. Obesity, overweight and ethnicity. Health Rep 2005;16:23-34.

27. Belanger-Ducharme F, Tremblay A. Prevalence of obesity in Canada. Obes Rev 2005; 6: $183-6$.

28. Perez CE. Health status and health behaviour among immigrants. Health Reports 2002;13(Suppl): 89-100.

29. Cairney J, Ostbye T. Time since immigration and excess body weight. Can J Public Health I999;90:120-4.

30. Goel MS, McCarthy EP, Phillips RS, et al. Obesity among US immigrant subgroups by duration of residence. JAMA 2004;292:2860-7.

3I. Lauderdale DS, Rathouz PJ. Body mass index in a US national sample of Asian Americans: effects of nativity, years since immigration and socioeconomic status. Int J Obes Relat Metab Disord 2000;24:1188-94.

32. Pijnenborg R, Vercruysse L, Hanssens M. The uterine spiral arteries in human pregnancy: facts and controversies. Placenta 2006;27:939-58

33. Beshiri R. Immigrants in rural Canada: 200I update. Rural and Small Town Canada Analysis Bulletin 2004;5(4):I-I4. Available: www.statcan.ca/english Ifreepub/2I-006-XIE/2I-006-XIE2004004.pdf (accessed 2007 Feb 28).

34. Krebs NF, Jacobson MS; American Academy of Pediatrics Committee on Nutrition. Prevention of pediatric overweight and obesity. Pediatrics 2003;112:424-30.

35. Evans WD, Renaud JM, Finkelstein E, et al. Changing perceptions of the childhood obesity epidemic. Am J Health Behav 2006;30:167-76.

36. Rooney BL, Schauberger CW. Excess pregnancy weight gain and long-term obesity: one decade later. Obstet Gynecol 2002;100:245-52.

Correspondence to: Dr. Joel G. Ray, Department of Medicine, St. Michael's Hospital, 30 Bond St., Toronto ON M5B IW8; fax 4I6 864-5485; rayj@smh.toronto.on.ca

Appendix 1: Region of origin of new immigrants to Ontario $1991-2001^{9}$

No. $(\%)$

Region

$n=1022365$

Asia

West Central Asia or Middle East

Eastern Asia

Southeast Asia

Southern Asia

Europe

Western Europe

Eastern Europe

Northern Europe

Southern Europe

Americas

North America

Central America

Caribbean or Bermuda

South America

Africa

Western Africa

Eastern Africa

Northern Africa

Central Africa

Southern Africa

Oceania

Other
$593740(58.1)$

$98795 \quad(9.7)$

$197795(19.3)$

$92875 \quad(9.1)$

$204275(20.0)$

206565 (20.2)

$13305 \quad(1.3)$

108340 (10.8)

$22525 \quad(2.2)$

$62395 \quad(6.1)$

$149720(14.6)$

$23765 \quad(2.3)$

$22830 \quad(2.2)$

$57845 \quad$ (5.7)

$45280 \quad(4.4)$

$69035 \quad(6.8)$

$14475 \quad(1.4)$

$30315 \quad(3.0)$

$15025 \quad(1.5)$

$\begin{array}{lll}3120 & (0.3)\end{array}$

$6100 \quad(0.6)$

$2930 \quad(0.3)$

$375 \quad(6.0)$ 
Appendix 2: Definition of study variables and covariates

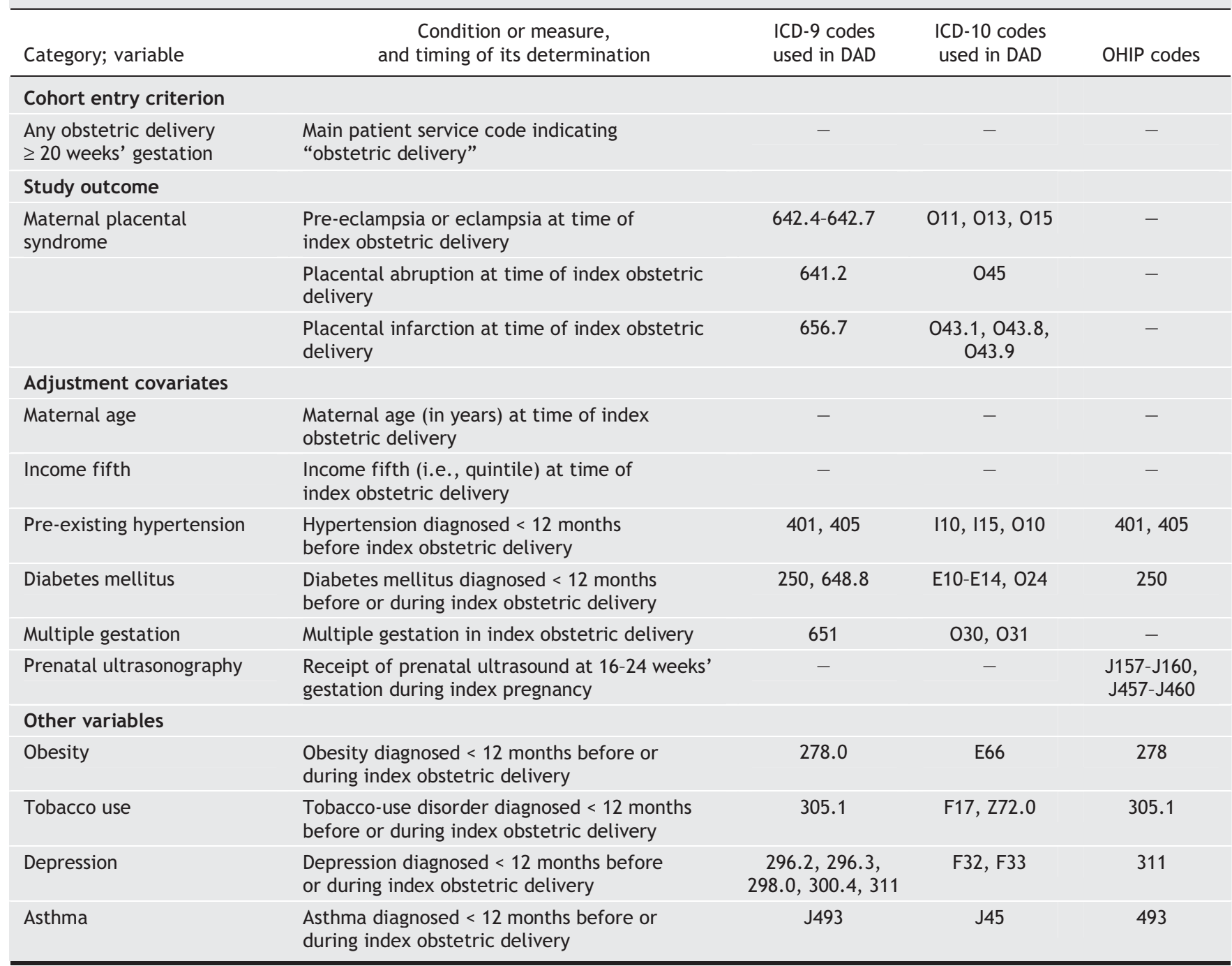

Note: ICD-9 and ICD-10 = International Classification of Diseases, 9th and 10th revisions; DAD = Discharge Abstract Database of the Canadian Institute for Health Information; $\mathrm{OHIP}=$ Ontario Health Insurance Plan. 